\title{
Calibrating a material model for AD995 alumina from plate impact VISAR profiles
}

\section{Y. Partom}

Institute for Advanced Technology, The University of Texas at Austin, 4030-2 W. Braker Lane, Austin, TX 78759, U.S.A.

Résumé-Nous présentous une validation/calibration d'un modèle de matériau pour l'alumina AD995. Nous utilisons les resultats de cinq expériences d'impact de plaques symétrique menées par Grady [1], désignées CE 56 á 60 . Notre modéle de matériau est semblable á celeu employé par Johnson et Holmquist [5]. Il a une courbe de rupture fragile pour le matériau sans endommagement, et une courbe d'écoulement pour le matériau ruiné (granuleux). La résponse iriscoplastique de matériau endommagé aux contraintes de cisaillement, au de la courbe d'écoulement quasistatique, est maxwellienne. Nous calibrons la résponse viscoplastique pour correspondre au test CE 58, puis vérifious la validité du modéle de matériau, en prédisant les résultats pour les quatre autres tests. Un asez bon accord est obtenu.

Abstract-We present a validation/calibration of a material model for AD995 alumina. We use five of Grady's symmetric impact test data designated CE56 to CE60. Our material model is similar to that employed by Johnson and Holmquist [5]. It has a fracture surface for the intact material, and a flow surface for the fractured (granularlike) material. The viscoplastic response of the fractured material to shear stresses beyond the quasistatic yield surface is Maxwellian. We calibrate the viscoplastic response to match test CE58, and then check the validity of the material model by predicting the results for the four other tests. Agreement is quite good.

\section{Introduction}

There has been a growing interest in understanding the response of ceramic materials in high velocity impact situations $[6,7,8]$. One way to gain such understanding is by comparing results of carefully designed and controlled plate impact tests [2,3,4]. Several material models for ceramics have been proposed, and some of them were implemented into wavecodes $[2,5,9,10]$. From these, attention has been focused on Steinberg's [2] and Johnson-Holmquist's [5] models.

Test data sometimes consist of several VISAR particle velocity histories obtained at different impact velocities. To calibrate a material model, a 1D wavecode is run for one of the tests and the model parameters are adjusted to match the data. With these parameters the code is then run for the other tests. Comparing the predicted histories to the data, conclusions about the merit of the material model can be drawn.

A brittle material model should include: a) equation of state; b) fracture surface to determine the conditions for the material to fracture, lose part of its strength (all at once or gradually), and become a granular-like material; and c) flow stress relation for the fractured material.

Parts $b$ and $c$ together are sometimes referred to as a strength model. Lately we have been using, in our long rod penetration modeling $[11,12,13]$, a strength model similar to that of Johnson-Holmquist [5]. In [14], we discuss qualitatively how this strength model would perform in planar impact situations. 
Recently we obtained from Grady [15] a set of VISAR histories from symmetric impacts of AD995 alumina. In a recent report, Mandell [4] applied the MESA wavecode with two different strength models to match these same histories. Here we try to match the compression parts of Grady's data using our own strength model. We do not use a wavecode. Instead, we assume that the compression parts are close to steady-state, and to match them we integrate the steady-state flow equations [16] which are ODEs.

In what follows we first outline Grady's data that we used, and our attempt to calibrate the pressure dependent flow stress directly from the data. We then write down the steady-state flow equations and describe the calibration procedure. Finally, we show the good agreement between the predicted histories and the data.

\section{Grady's Data}

The VISAR histories supplied by Grady are from five symmetric plate impacts (alumina on alumina) designated CE56 to CE60. The target (and impactor) material is AD995 alumina with the following properties: density $=3.890 \mathrm{~g} / \mathrm{cc}$, longitudinal sound speed $=10.556 \mathrm{~km} / \mathrm{s}$, transverse sound speed $=6.244 \mathrm{~km} / \mathrm{s}$. The impactor is backed by polyurethane foam with density of $0.320 \mathrm{~g} / \mathrm{cc}$ (except CE60 for which it is $0.640 \mathrm{~g} / \mathrm{cc}$ ). The target is backed by a LiF window. The geometry of the set-up and the impact velocities are given in Table 1.

Table 1. Geometry and Impact Velocities of Grady's Tests CE56 to CE60

\begin{tabular}{cccc}
\hline \hline No. & $\begin{array}{c}\text { Impact Velocity } \\
(\mathbf{k m} / \mathbf{s})\end{array}$ & $\begin{array}{c}\text { Target Thickness } \\
(\mathbf{n m})\end{array}$ & $\begin{array}{c}\text { Projectile Thickness } \\
(\mathbf{m m})\end{array}$ \\
\hline 56 & 0.544 & 10.007 & 5.008 \\
57 & 1.019 & 10.006 & 5.019 \\
58 & 1.588 & 10.008 & 5.008 \\
59 & 2.030 & 10.007 & 5.013 \\
60 & 2.329 & 9.998 & 5.005 \\
& & \\
target diameter: $76.2 \mathrm{~mm}$ & & \\
impactor diameter: $87 \mathrm{~mm}$ & & \\
impactor backing thickness $=8 \mathrm{~mm}$ \\
window dimensions: diameter $=50.8 \mathrm{~mm}$, length $=25.4 \mathrm{~mm}$
\end{tabular}

\section{Pressure Dependence on the Flow Stress}

As for granular materials, we assume that for fractured ceramics as well, the quasistatic flow stress (Yqs) increases with pressure. This is shown schematically in Figure. 1.

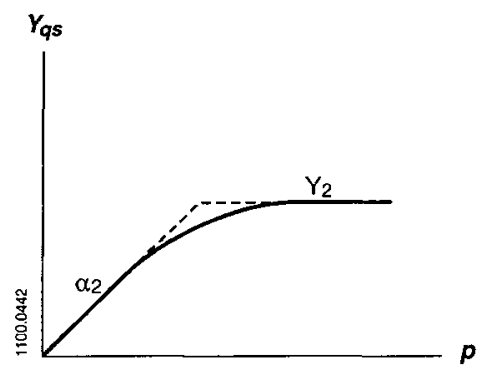

Figure 1. Schematic plot of the quasistatic flow stress of a fractured ceramic as a function of pressure.

Yqs measures the flow stress in the usual von-Mises sense, $P$ is the pressure, $\alpha_{2}$ is the initial slope, and $Y_{2}$ is the saturation plateau level. The broken and smooth lines are: 


$$
\begin{aligned}
& \mathrm{Yqs}=\min \left(\alpha_{2} \mathrm{P}, \mathrm{Y}_{2}\right) \\
& \mathrm{Y}_{\mathrm{qs}}=\mathrm{Y}_{2}\left(1-\exp \left(-\frac{\alpha_{2}}{\mathrm{Y}_{2}} \mathrm{P}\right)\right)
\end{aligned}
$$

The broken line is a frequently used piecewise linear approximation. For $\sigma^{\prime}>2 / 3$ Yqs $\left(\sigma^{\prime}=\right.$ flow direction stress deviator component) the fractured ceramic flows. We assume that when it flows, the plastic deformation rate $\mathrm{d}^{\mathrm{p}}$ (flow direction component) is given by:

$$
\mathrm{d}^{\mathrm{p}}=\lambda\left(\sigma^{\prime}-2 / 3 \mathrm{Yqs}\right)
$$

where $\lambda$ may be pressure dependent.

Assuming the adiabatic hydrostat of the ceramic $P(\rho)$ or $P(\varepsilon),\left(\varepsilon=1-\rho_{0} / \rho\right)$, to be known, it is

Table 2. Plateau Level Values Obtained by Impedance Mismatch at the Window Interface

\begin{tabular}{cccccc}
\hline \hline $\mathbf{C E}$ & $\mathbf{u}_{\mathbf{x}} \mathbf{k m} / \mathbf{s}$ & $\mathbf{u}=\mathbf{1} / \mathbf{2} \mathbf{u}_{\mathbf{i m p}} \mathbf{~ k m} / \mathbf{s}$ & $\boldsymbol{\sigma} \mathbf{~ G P a}$ & $\boldsymbol{\varepsilon} \%$ & $\mathbf{P ~ G P a}$ \\
\hline 56 & 0.382 & 0.272 & 10.29 & 2.82 & 6.57 \\
57 & 0.696 & 0.509 & 19.07 & 5.31 & 12.60 \\
58 & 0.99 & 0.794 & 25.47 & 9.77 & 23.94 \\
59 & 1.22 & 1.015 & 30.98 & 13.15 & 32.96 \\
60 & 1.32 & 1.164 & 31.22 & 17.39 & 44.88
\end{tabular}

where $\mathfrak{u}_{\mathrm{x}}$ are the VISAR plateau values

possible to determine points on Yqs (P) from the plateau levels of the data and the impact velocities. In [17] we outline in detail the procedure to do this. The results obtained are given in Table 2.

We see that for CE58 $\sigma^{\prime}=1.5 \mathrm{GPa}$ while for CE59 and CE60 $\sigma^{\prime}<0$. This of course is not appropriate. We have also shown that this outcome is not varied even by drastic changes of the hydrostat and the shear modulus of the ceramic. We convinced ourselves that it results from the sensitivity of Yqs (P) obtained in this way to small inconsistencies between impact velocities and plateau levels. We therefore proceed by assuming Yqs (P) to be known, and by using only the VISAR data (ignoring the measured impact velocities).

\section{Matching the Compression Parts of the VISAR Histories}

Relying on data from [18], we assume that $Y_{2}=5.5 \mathrm{GPa}$. As $\alpha_{2}$ is not known, we did the matching with two values: $\alpha_{2}=0.5$ and 1.0, hoping that the matching results are not sensitive to small variations in $\alpha_{2}$. We use the smooth Yqs (P) curve (equation (1.2)).

The steady-state flow equations for a Maxwellian viscoplastic solid are derived in detail in [16]. They are:

$$
\begin{aligned}
& \dot{\sigma}=\frac{2 G d^{p}}{M} ; \dot{u}=\frac{2 G d^{p}}{\rho_{o} U M} ; \dot{\varepsilon}=\frac{2 G d^{p}}{\rho_{o} U^{2} M} \\
& M=\frac{C_{L}^{2}}{U^{2}}-1
\end{aligned}
$$

where: $\sigma=$ stress, $\mathrm{u}=$ particle velocity, $\varepsilon=$ strain (defined above), $\mathrm{C}_{\mathrm{L}}=$ Lagrangian wave speed, $\mathrm{G}=$ sheer modulus, $U=$ Lagrangian plastic wave speed.

Integration of these equations (which is along the Rayleigh line) starts from the HEL point (which is the $1 \mathrm{D}$ strain point on the fracture surface). 
To perform the integration we first determine $U$ by impedance mismatch at the window interface. The equations for that are outlined in detail in [17]. We then use a standard ODE solver to integrate equations (3) from the HEL to the plateau level. Obtaining the right plateau level is a check on the determination of $U$.

The only parameter left to be calibrated from the data is $\lambda$ in equation (2). Initially we assumed a

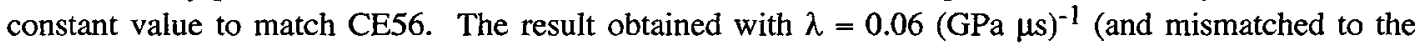
window interface) is shown in Figure 2. On the same plot we copied the VISAR trace and we see that agreement is quite good. It is important to note that the initial finite slope (characteristic of particle velocity and stress histories in ceramics $[8,19,20]$ results directly from the strength drop upon fracture. In metals there is generally no strength drop upon yielding, and these steady-state histories are "s" shaped with an initial zero slope.

Next we applied the same parameters to CE57, and the comparison is shown in Figure 3. We see a significant disagreement. While the computed curve is knee-shaped as before, the VISAR curve becomes steeper with amplitude. Observing the other VISAR histories, we see that they become even steeper for the higher impact velocities. We conclude that to model this behavior we need $\lambda$ to increase with pressure. We first tried a moderate dependence like:

$$
\lambda=\lambda_{\mathrm{o}}+\lambda_{1} \mathrm{P}
$$

but the slope of the $u(t)$ curve predicted did not increase fast enough. We ended up using a strong dependence:

$$
\lambda=\lambda_{\mathrm{o}} \exp \lambda_{1}(\mathrm{P}-\mathrm{Ph})
$$

where $\mathrm{Ph}$ is the pressure at the HEL.

The values of $\lambda_{\mathrm{o}}, \lambda_{1}$ needed to match CE58 are given in Table 3 .

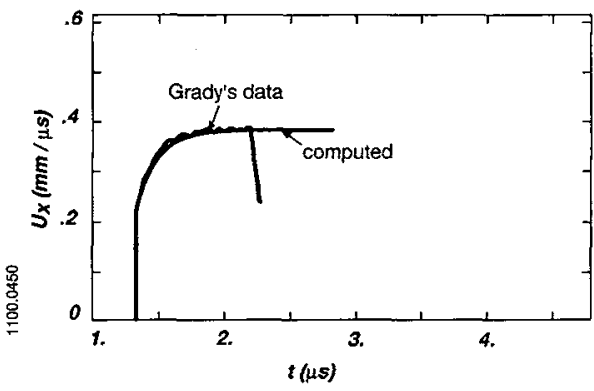

Figure 2. Matching the loading part of the VISAR CE56 trace. Constant $\lambda=0.060$ (GPa $\mu$ s) ${ }^{-1} \mathbf{u}_{\mathbf{x}}$.

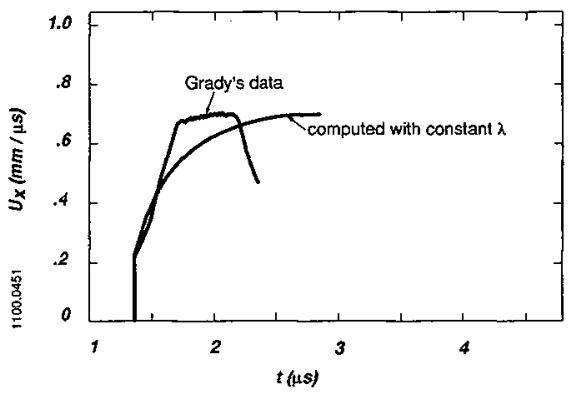

Figure 3. Matching the loading part of the VISAR CE57 trace. Constant $\lambda=0.060(\text { GPa } \mu)^{-1}$.

Table 3. Values of $\lambda_{0}$ and $\lambda_{1}$

\begin{tabular}{ccc}
\hline \hline$\alpha_{2}$ & $\lambda_{\mathbf{0}}(\mathbf{G P a} \mu \mathbf{s})^{-1}$ & $\lambda_{\mathbf{1}}(\mathbf{G P a})^{-1}$ \\
\hline 0.5 & 0.03 & 0.26 \\
1.0 & 0.05 & 0.32 \\
\hline
\end{tabular}

The $\alpha_{2}=1.0$ results turned out to agree slightly better with the data (for CE56) than the $\alpha_{2}=0.5$ results. We show the agreement of the results in Figure 4. (The results for $\alpha_{2}=0.5$ are documented in [17]). We see that the agreement is extremely good (in view of the experimental error). 

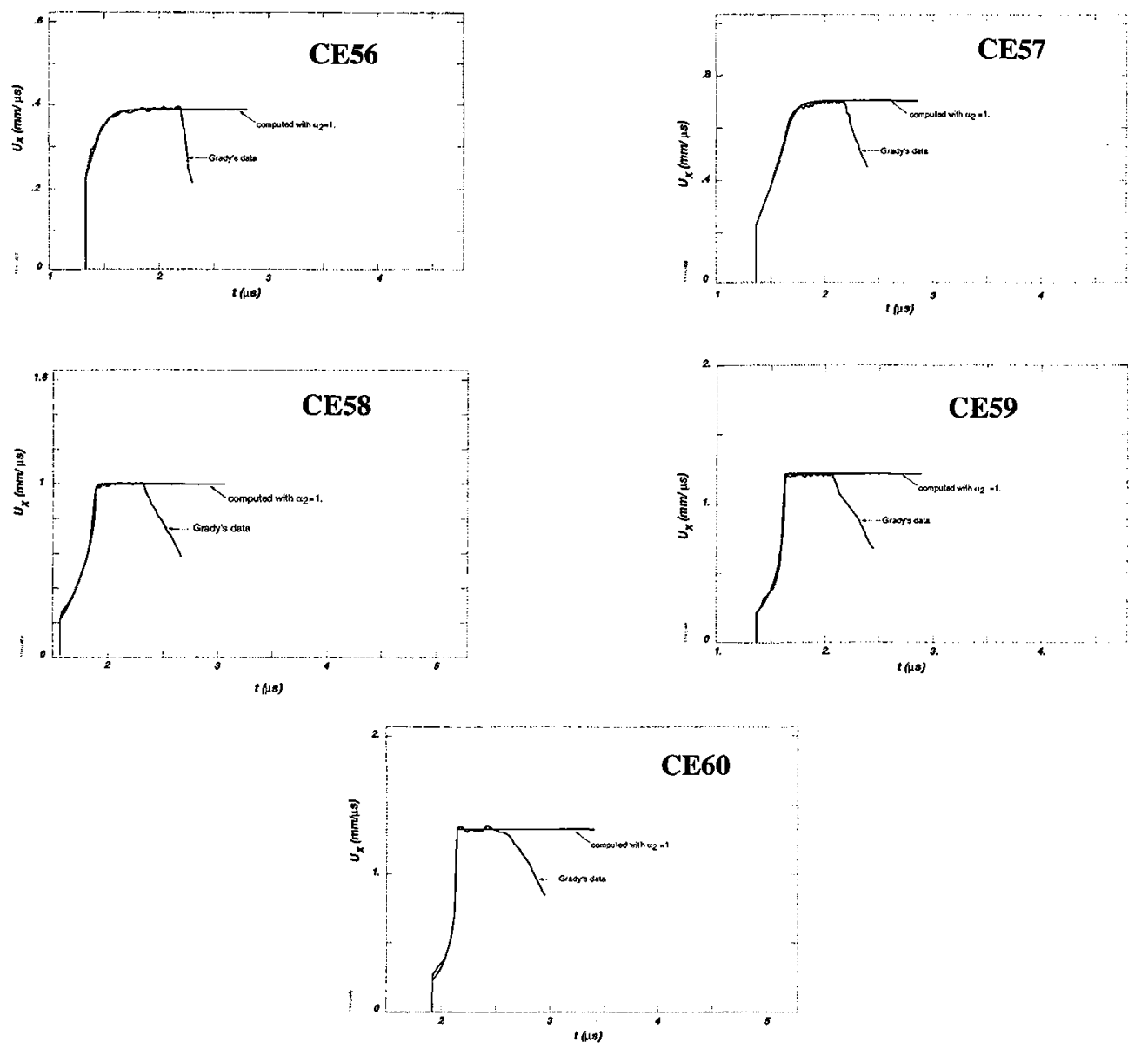

Figure 4. Results for $\alpha_{2}=1, \lambda_{0}=0.05(\mathrm{GPa} \mu \mathrm{s})^{-1}$, and $\lambda_{1}=0.32 \mathrm{GPa}^{-1}$.

\section{Conclusions}

We are using $1 \mathrm{D}$ steady-state flow equations to match the compression parts of Grady's VISAR histories for symmetric plate impacts of AD995 alumina. The material strength model is represented by a pressure dependent fracture surface (not used here), and a pressure dependent quasistatic yield surface. The viscoplastic response is Maxwellian, and the flow curve slope $(\lambda)$ increases with pressure. From the matching process we draw the following conclusions:

- Extracting points on the Yqs (P) curve from the data may be sensitive to small inconsistencies between plateau levels and impact velocities.

- The partial loss of strength upon fracture is responsible for the finite initial slope of the plastic wave history curves.

- Using a strong (exponential) pressure dependence for the flow curve slope $(\lambda)$ makes it possible to match the knee-shaped curves at low impact velocities as well as the steep curves at high impact velocities.

- The slope of the Yqs (P) curve $\left(\alpha_{2}\right)$ influences the matching of the low impact velocity histories. 


\section{Acknowledgment}

I thank Dr. Dennis Grady for kindly providing me with his VISAR data, and for reviewing the original report [17] and discussing some of the results.

This work was supported by the U.S. Army Armament Research, Development and Engineering Center (ARDEC) under contract DAAA21-90-D-0009.

\section{References}

[1] D. E. Grady and J. L. Wise, "Dynamic Properties of Ceramic Materials," SNL Report, SAND93-610, 1993.

[2] D. J. Steinberg, "Computer Studies of the Dynamic Strength of Ceramics," Shock Compression of Condensed Matter, edited by S. C. Schmidt et al., p. 447, North Holland, 1992.

[3] D. A. Mandell and R. Henninger, "Evaluation of Two Ceramic Models in the MESA Code," LANL Report, LA-12267, 1992.

[4] D. A. Mandell, "Prediction of Alumina Penetration," LANL Report, LA-12520, 1993.

[5] G. R. Johnson and T. J. Holmquist, "A Computational Model for Brittle Materials Subjected to Large Strains, High Strain Rates, and High Pressures," Shock Wave and High Strain Rate Phenomena in Materials, edited by M. A. Meyers et al., Marcel Dekker, 1992.

[6] M. A. Dietenberger et al., "A Use of Microphysical Fracture Model to Describe Ceramic Material upon Impact," Shock Compression of Condensed Matter, edited by S. C. Schmidt et al., p. 457, Elsevier, 1990.

[7] J. L. Kroupa and A. M. Rajendran, "The Use of Grady-Kipp Type Fragmentation Model to Describe the Impact Behavior of Ceramic Materials," Shock Compression of Condensed Matter, edited by S. C. Schmidt et al., p. 911, Elsevier, 1990.

[8] Z. Rosenberg, "The Response of Ceramic Materials to Shock Loading," Shock Compression of Condensed Matter, edited by S. C. Schmidt et al., p. 439, North Holland, 1992.

[9] L. G. Margolin, "Microphysical Models for Inelastic Material Response," Int. J. Engng. Sci., vol. 22, p. 1171, 1984.

[10] L. S. Costin and C. M. Stone, "Finite Element Material Model for Microfracture Damaged Brittle Rock," SNL Report, SAND87-1227, 1987.

[11] Y. Partom, "Ceramic Armor-Resistance to Long-Rod Penetration and its Dependence on Projectile Velocity" IAT.R 0017, 1993.

[12] Y. Partom, "Efficiency of Lateral Self Confinement in Metal and Ceramic Targets," IAT.R 0019, 1993.

[13] Y. Partom and D. Littlefield, "Validation of the Cavity Expansion Resistance Model for Ceramic Targets with Computer Simulations," IAT.R 0025, 1993.

[14] Y. Partom, "Fracture Stress and Flow Stress for Alumina AD85 as a Function of Pressure," IAT.TN 0006.

[15] D. Grady, "VISAR Shock-Wave Profiles," unpublished.

[16] Y. Partom, "Elastic Precursor Decay Calculation," J. Appl. Phys., vol. 59, p. 2716, 1986.

[17] Y. Partom, "Calibrating a Strength Model for AD995 Alumina from Plate Impact VISAR Profiles," IAT.R 0029, 1993.

[18] Z. Rosenberg et al., "The Shear Stress of Shock Loaded Alumina as Determined with Longitudinal and Transverse Manganin Gauges," J. Appl. Phys., vol. 62, p. 1120, 1987.

[19] D. Yaziv et al., "Shock Structure and Precursor Decay in Commercial Alumina," Shock Waves in Condensed Matter, Monteray, p. 2397, 1987.

[20] Z. Rosenberg et al., "Dynamic High Pressure Properties of AlN Ceramic as Determined by Flyer Plate Impact," J. Appl. Phys., vol. 70, p. 167, 1991.

Last minute remark. Analysis in this paper assumes the material to flow plastically above the HEL, which implies the existance of an elastic precursor decay. Rosenberg et al., and Yaziv et al., found elastic precursor decay in alumina using manganin gauges. Cagnoux et al., and Grady (still unpublished) found no elastic precursor decay in alumina using VISAR. So the issue stays unresolved. 